\title{
Comparison of the Effects of Isoflurane and Sevoflurane General Anaesthesia after Induction by Propofol on Clinical and Physiological Measurements in Calves*
}

\author{
Selvinaz Yakan' \& Ozgur Aksoy²
}

\begin{abstract}
Background: In veterinary surgical operations for cats and dogs, inhalation anaesthesia is known to be a good option for general anaesthesia in long operations or emergency cases. Studies have revealed that during inhalation anaesthesia, the heart and respiratory functions of the animals are more stable compared to injectable anaesthesia. However, there are few studies performed with the use of inhalation anaesthesia in ruminants. In this research, the goal is to evaluate the effects of isoflurane and sevoflurane after induction with propofol in calves based on clinical and physiological parameters and to find a more reliable strategy for general anaesthesia in ruminants.

Materials, Methods \& Results: The research was carried out on 30 calves, from new-born up to 3-month-old, undergoing surgery operation. Each group consisted of 15 animals that were divided as isoflurane and sevoflurane. For premedication, atropine was administered at a dose of $0.04 \mathrm{mg} / \mathrm{kg}$ via subcutaneous injection in calves. For induction, $15 \mathrm{~min}$ after atropine application, propofol was given at $5-6 \mathrm{mg} / \mathrm{kg}$ via intravenous infusion. Then, endotracheal intubation was performed and inhalation anaesthesia began at $5 \mathrm{~min}$ after induction. In the isoflurane group, the onset of anaesthesia concentration was set to 3-5\% and the maintenance was set to a concentration of 1.5-3\%. In the sevoflurane group, the onset of anaesthesia concentration was set to 5-7\% and the maintenance was set to a concentration of 2.5-4\%. To monitor the calves, the heart rate (HR), the pulse rate (PR), the systolic blood pressure (SBP), the diastolic blood pressure (DBP), the respiratory rate (RR), the rectal temperature (RT) and the electrocardiogram (ECG) measurements were recorded before anaesthesia, the premedication, the induction periods, at $5,15,30,45,60$, and $75 \mathrm{~min}$ after the onset of inhalation anaesthesia during the operation period. Blood samples were taken before anaesthesia, premedication, induction periods, at 30 and 75 min during the operation and the red blood cell (RBC) count, white blood cell (WBC) count, the amount of haemoglobin (HGB), the haematocrit concentration (HCT), and the platelet (PLT) count were evaluated. Based on the findings, isoflurane and sevoflurane suppressed the cardiovascular system minimally. Both anaesthetic agents caused decreases that did not exceed the physiological limits compared to the measurements taken before the initiation of anaesthesia. Although no significant differences were detected between the groups $(P>0.05)$ at clinical parameters, the RT differences were regarded as statistically significant according to the measurements that were taken before anaesthesia at all measurement times $(P<$ 0.05). In both groups, the changes that occurred in the $\mathrm{P}$ wave, the PR interval, and in the QRS, R and $T$ waves remained within the reference values given in the literature. Both anaesthetic agents have similar effects on the ECG. The dramatic no changes throughout anaesthesia in terms of the amount of HGB and HCT, the RBC, the WBC, and the PLT were not statistically significant, which may be associated with good tissue perfusion.

Discussion: Since no serious complications occurred with either anaesthetic option, we have concluded that isoflurane and sevoflurane have similar effects on the cardiopulmonary systems of calves. In addition, the effects of propofol, which is used for induction, have been evaluated and observed and this drug is an effective and reliable option to initiate inhalation anaesthesia. The research on the use of this anaesthetic in calves is limited and most of the existing studies investigated its combination with injectable anaesthetics. As a result, in this research, we concluded that isoflurane and sevoflurane induce similar physiological measurement results, blood parameters, and ECG results and that both anaesthetics cause minimal complications.
\end{abstract}

Keywords: calves, propofol, isoflurane, sevoflurane.

DOI: $10.22456 / 1679-9216.92279$

Received: 8 January 2019

Accepted: 20 April 2019

Published: 18 May 2019

*Article based on a Thesis submitted by the first author in partial fulfillment of requirements for the Doctor's Degree. 'Department of Animal Health, Eleskirt Celal Oruc Animal Production School, Agri Ibrahim Cecen University, Agri, Turkey. ${ }^{2}$ Faculty of Veterinary Medicine, Department of Surgery, Kafkas University, Kars, Turkey. CORRESPONDENCE: S. Yakan [syakan@ gmail.com - Tel: +90 47221598 63]. Department of Animal Health, Eleskirt Celal Oruc Animal Production School, Agri Ibrahim Cecen University. TR-04100 Agri, Turkey. 


\section{INTRODUCTION}

One of the methods used for general anaesthesia is inhalation anaesthesia $[25,35,38]$. Studies have revealed that during general inhalation anaesthesia, the heart and respiratory functions of the animals are more stable compared to injectable anaesthesia [1,5,16,31]. Isoflurane and sevoflurane are the most ideal inhalation anaesthetics with optimal features and are widely used in clinical practice $[25,27,36]$. Because the blood/gas solution coefficient of isoflurane is low, anaesthetic induction and exit from anaesthesia very fast. At the end of anaesthesia, due to low blood and tissue solubility and metabolic balance, metabolic end product is very small and therefore low toxic effect. Depending on the dose, it suppresses the myocardial contractility $[3,6,25,34,36]$. Sevoflurane provides a quick induction and recovery from anaesthesia similar to isoflurane. Its effect on the cardiovascular system is similar to isoflurane. Arterial blood pressure and the systemic vascular resistance can decrease depending on the dose $[8,13,15,25,34]$. Propofol is used with the goal of induction and causes rapid loss of consciousness in 20 to $40 \mathrm{~s}$ following IV administration [11]. The loss of consciousness occurs very quickly in animals and the recovery from anaesthesia is rapid [30,33]. It is compatible with pre-anaesthetic and anaesthetic agents. Due to this feature, it can be used with the inhalation anaesthetics. It does not accumulate or cause excitation in the short-term or with repeated applications $[9,16,20]$.

In this research, the objective is to evaluate the effects of isoflurane and sevoflurane anaesthesia after induction with propofol in calves based on clinical and physiological parameters and to find a more reliable strategy for general anaesthesia in ruminants.

\section{MATERIALS AND METHODS}

\section{Animals}

This study was carried on a total of 30 calves, from new-born up to 3-month-old, of different races and genders undergoing surgical operations at Kafkas University Faculty of Veterinary Medicine Department of Surgery. Calves were randomly divided into two groups, as isoflurane and sevoflurane.

\section{Anaesthesia procedures}

Before anaesthesia at $15 \mathrm{~min}, 0.04 \mathrm{mg} / \mathrm{kg}$ of atropine (Atrol- $\mathrm{R}^{\circledR} 20 \mathrm{~mL}$ vial) ${ }^{1}$ was given to the calves subcutaneously as premedication, which has already been evaluated and determined as suitable for the operation. This period is called the premedication period in this research. 15 min later, propofol (Propofol ${ }^{\circledR} 1 \%$ $20 \mathrm{~mL}$ enj) $)^{2}$, a short-term injectable anaesthetic for anaesthesia induction, was administered at a dose of $5-6 \mathrm{mg} / \mathrm{kg}$ to the calves intravenously (IV) through the Vena jugularis. This application period is called the induction period in this research. For these cases with propofol anaesthesia and performed endotracheal intubation according to the technique [17,29], a mixture of $100 \% \mathrm{O}_{2}$ and volatile liquid anaesthesia was administered at $5 \mathrm{~min}$ after the propofol injection. Throughout the operation, the animals were maintained under anaesthesia with spontaneous ventilation. In the isoflurane (Isoflurane $\left.{ }^{\circledR}\right)^{3}$ group, the anaesthesia $(\mathrm{n}=15$ calve/group) was initiated at a concentration of 3-5\%. When deep anaesthesia symptoms were observed, isoflurane was reduced to a concentration of $1.5-3 \%$ for maintenance. In the sevoflurane (Sevoflurane Likit $\left.{ }^{\circledR}\right)^{4}$ group, the anaesthesia of ( $\mathrm{n}=15$ calve/group) was initiated at a concentration of $5-7 \%$ and then maintained at $2.5-4 \%$ concentration. When the operation was complete, the device with the endotracheal tube was disconnected and the animal was allowed to breathe atmospheric air. The tube that had been located in the trachea was removed after the swallowing reflex was observed.

Analysis

To determine the cardiopulmonary effects of the anaesthetic agents, an appropriately sized cuff for the oscillometric blood pressure monitor was placed on the Arteria axillaris on the forearm. The systolic blood pressure (SBP), diastolic blood pressure (DBP), mean arterial blood pressure (MABP), heart rate (HR) and also the electrocardiogram (ECG) values were measured from the screen of the monitor (Veterinary Monitor $\left.{ }^{\circledR}\right)^{5}$ were recorded. By fixing the pulse oximetry probe on the tongue, the oxygen saturation, pulse rate $(\mathrm{PR})$, and respiratory rate (RR) were observed. The $\mathrm{RR}$ was monitored by observing the movements of the reservoir balloon and rib. The ECG records were taken, anaesthesia before, the premeditation and the induction periods and at 5, 15, 30, 45, 60 and 75 min after the initiation of inhalation anaesthesia. The calves were placed on the operation table for ECG testing either in the ventro-dorsal (VD) or in the latero-lateral (LL) position according to the requirements of the operation. 
The red electrode, which was linked to the monitor, was fixed to the cranial side of the right scapula, the yellow electrode was fixed to the cranial side of the left scapula, the green electrode was fixed to the skin of the left hind legend the black electrode was fixed to the right hind leg grip. The ECG device was set at $\mathrm{Mv}=10 \mathrm{~mm}$ and the printing speed was set at 25 $\mathrm{mm} / \mathrm{s}$. The electrocardiograms were printed with lead II derivations. During each ECG test, the heart rate per minute, the P, PR, and T intervals (s), the QRS complex and the volume of the $\mathrm{R}$ wave $(\mathrm{Mv})$ were observed in the lead II derivation. The rectal temperatures (RT) of the animals were measured by the placement into the rectum of the temperature probe linked to the monitor. Before anaesthesia and the premedication and induction periods and at 5, 15, 30, 45, 60 and 75 min after the initiation of inhalation anaesthesia, the following parameters were recorded: the HR, PR, SBP, DBP, MABP, RR, RT and ECG values.

Blood samples for the haematological examination were taken and stored in sterilized $2.5 \mathrm{~mL}$ tubes with Ethylenediaminetetraacetic acid (EDTA) before anaesthesia and the premedication and induction periods and at 30 and 75 min after the application of inhalation anaesthesia. The red blood cell (RBC) count, white blood cell (WBC) count, the amount of haemoglobin (HGB), the haematocrit concentration (HCT), and the platelet (PLT) count were evaluated using the automatic counter (Abacus Junior Vet 5)

\section{Statistical analysis}

All of the data acquired from the research was evaluated using the packaged software SPSS-16 (Statistical Package for Social Sciences). The data were tested for normality. The nonparametric data were tested by the Kruskal-Wallis test and the normally distributed data were tested by the One-way ANOVA analysis of variance method. $P<0.05$ was set as the level of significance. The data are expressed as the mean \pm standard error (SE).

\section{RESULTS}

\section{The haemodynamic and respiratory measurements find- ings}

For the hemodynamic and respiratory parameters, the HR, PR, SBP, DBP and MABP, RR, and RT were evaluated. The measurement results of these parameters are provided in Table 1.

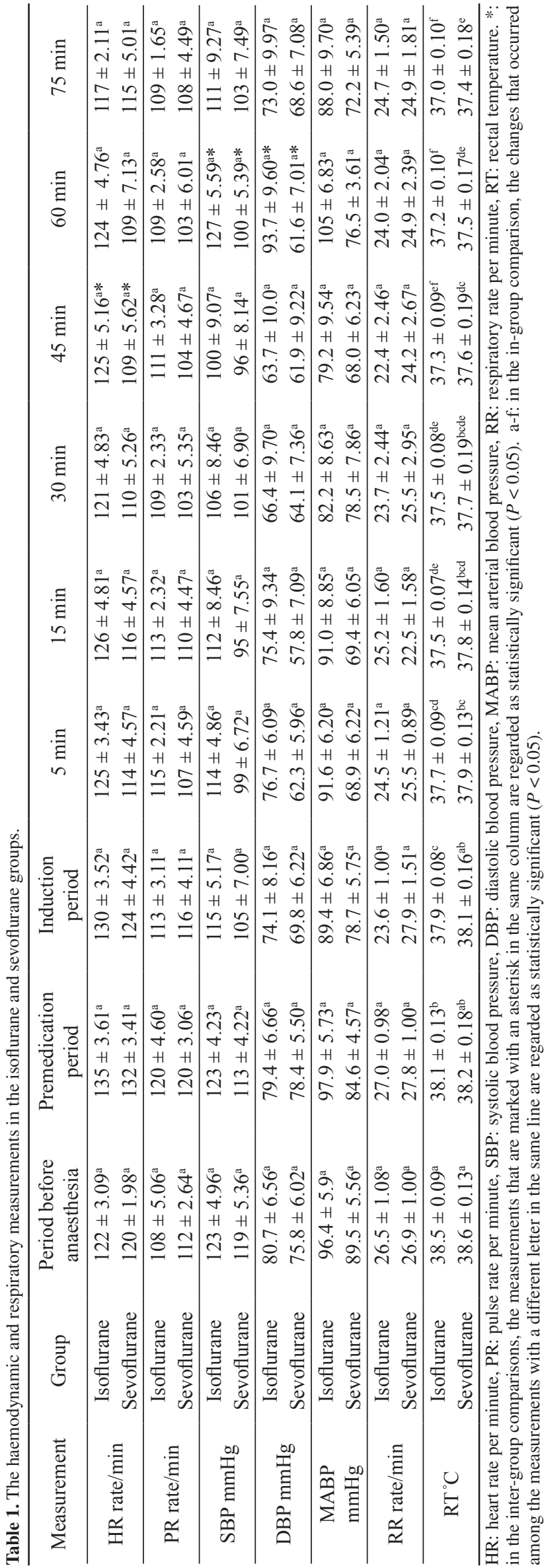


The throb and cardiac rhythm were regular before the administration of anaesthesia in the isoflurane and sevoflurane groups. After the atropine, the HR increased in all of the animals. Although not statistically significant, the increased HR in the isoflurane group was greater than in the sevoflurane group. The changes that occurred in the HR between the isoflurane and sevoflurane groups before anaesthesia, during the premedication period, and at 5, 15, 30, 60 and $75 \mathrm{~min}$ after the initiation of inhalation anaesthesia were not considered statistically significant $(P>0.05)$, but the changes between the groups at 45 min were significant $(P<0.05)$. In addition, in both groups, the in-group comparisons were not statistically significant $(P>$ $0.05)$.

In terms of the PR, a statistically significant difference was not detected either between the groups or in each group itself $(P>0.05)$. In the isoflurane and sevoflurane groups, the pulse frequency increased during the premedication period due to the application of atropine. This increase continued into the physiological limits, but it was not statistically significant $(P>0.05)$.

Based on the findings, isoflurane and sevoflurane suppressed the cardiovascular system minimally. Both anaesthetic agents caused decreases that did not exceed the physiological limits compared to the measurements taken before the initiation of anaesthesia. In the comparisons between the groups, the changes that occurred in the SBP before anaesthesia, during the premedication and induction periods, and at 5, 15, 30, 45 and $75 \mathrm{~min}$ after the initiation of inhalation anaesthesia were not significant $(P>0.05)$. In the comparisons between the groups, the changes that occurred at $60 \mathrm{~min}$ were statistically significant $(P<0.05)$. Although the decrease that occurred in the SBP was not statistically significant, it was greater in the sevoflurane group. In both groups, no statistically significant difference was detected $(P>0.05)$.

In the isoflurane and sevoflurane groups, the DBP decreased into the physiological limits (Table 1), but this was not regarded as statistically significant $(P$ $>0.05)$. The changes that occurred between the groups at $60 \mathrm{~min}$ were considered statistically significant $(P$ $<0.05)$. Although the decrease in the DBP was not statistically significant, it was greater in the sevoflurane group. The in-group comparisons of the measurements of the intervals with isoflurane and sevoflurane were not considered significant $(P>0.05)$.
The changes that occurred in the RR during the inhalation anaesthesia period proceeded into the physiological limits. The changes that exceeded the physiological limits in terms of the RT and deepness could be regulated by artificial respiration from the reservoir balloon of the anaesthesia device without the need for medical therapy. Both the in-group and intergroup comparisons of isoflurane and sevoflurane were not considered statistically significant $(P>0.05)$.

In both groups, a $1-2^{\circ} \mathrm{C}$ decrease in the RT was observed. Although no significant differences were detected between the isoflurane and sevoflurane groups $(P>0.05)$, in each group, the temperature differences were regarded as statistically significant according to the measurements that were taken before anaesthesia at all sampling times $(P<0.05)$ [Table 1].

\section{Electrocardiogram (ECG) measurements findings}

For the ECG findings, the $\mathrm{P}$ wave, the PR interval, and the measurements of the QRS, R, and $\mathrm{T}$ waves are provided (Table 2). In the isoflurane and sevoflurane groups, the level of the $\mathrm{P}$ wave proceeded into the physiological limits. The $\mathrm{P}$ wave level between the groups and the changes that occurred in the second PR interval in both anaesthetic groups were not regarded as statistically significant $(P>0.05)$. In both anaesthesia groups, the in-group $P$ wave level and the changes that occurred in the second PR interval were not regarded as statistically significant $(P>0.05)$. In the isoflurane and sevoflurane groups, the changes that occurred in the QRS wave proceeded into the physiological limits. The changes in the QRS wave were not statistically significant between the groups $(P>0.05)$. In the isoflurane anaesthesia group, the QRS wave changes that occurred at all times were not considered statistically significant $(P>0.05)$. In the sevoflurane anaesthesia group, before anaesthesia administration and at $75 \mathrm{~min}$, the changes that occurred in the QRS wave level were considered statistically significant $(P<0.05)$. In the isoflurane and sevoflurane groups, the changes that occurred in the $\mathrm{R}(\mathrm{mV})$ and $\mathrm{T}(\mathrm{s})$ values remained between the reference limits. In the comparison of the groups, the changes that occurred in the $\mathrm{R}(\mathrm{mV})$ and $\mathrm{T}(\mathrm{s})$ values were not regarded as statistically significant $(P>0.05)$. In the comparison of both anaesthetics, the changes in the $\mathrm{R}(\mathrm{mV})$ and $\mathrm{T}$ (s) values were not regarded as statistically significant $(P>0.05)$. 


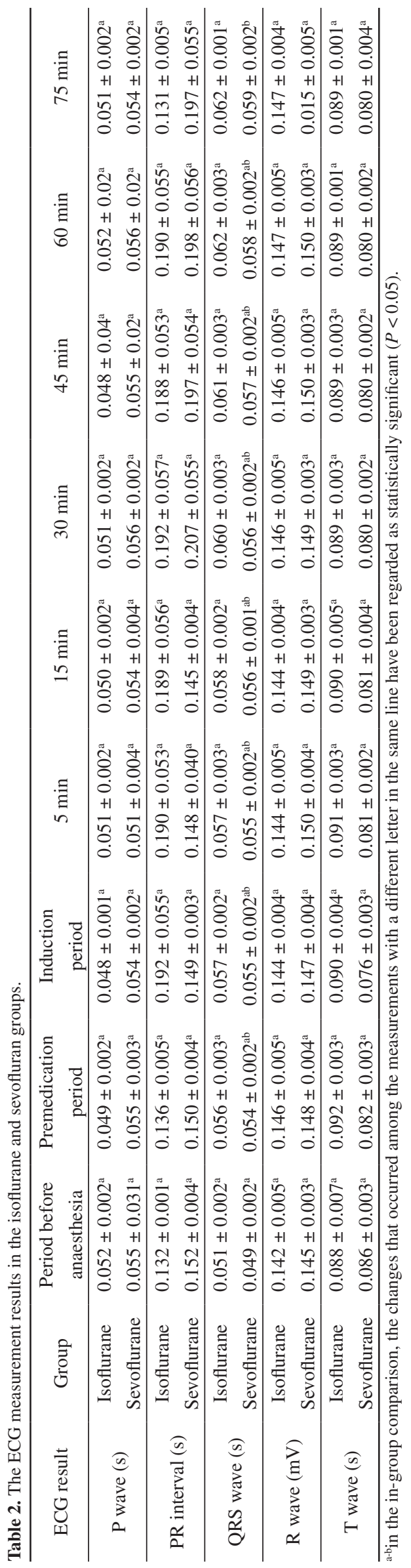

\section{Haematological measurements findings}

For the haematological findings, the changes that occurred in the values of the RBC, WBC, HGB, HCT, and PLT were compared (Table 3). RBC and WBC measurement results were not regarded as statistically significant either in-group or between the groups $(P>0.05)$. In the $\mathrm{RBC}$ in-group comparison, the results of the intertemporal measurements were not considered statistically significant $(P>0.05)$. In the $\mathrm{WBC}$ in-group comparison in the isoflurane group, the results of the intertemporal measurements were not considered statistically significant $(P>0.05)$. In the sevoflurane group, for the in-group comparison of the WBC count, significant differences were detected before the administration of anaesthesia and at $75 \mathrm{~min}$ compared to the WBC value during the premedication period $(P<0.05)$. The WBC count at 75 min decreased compared to the measurements before the administration of anaesthesia and compared to the premedication period measurement. According to the HGB and HCT measurement results, the intergroup comparison for the isoflurane and sevoflurane groups were not regarded as statistically significant $(P>0.05)$. The intertemporal measurement results of the HGB and HCT in-group comparisons for the isoflurane and sevoflurane groups were not considered statistically significant $(P>0.05)$. According to the measurement results of the PLT count, the intergroup measurement results were not considered statistically significant $(P>0.05)$. The PLT count in the in-group comparisons, based on the results of the intertemporal measurements, were not considered statistically significant $(P>0.05)$.

\section{DISCUSSION}

The depressive effects of isoflurane and sevoflurane on the cardiovascular and respiratory systems are known to be less severe compared to other anaesthetics $[13,18,25,28,35]$. These anaesthetics are advantageous because they allow for the maintenance of stable arterial blood pressure and cardiac performance and they no sensitize the myocardium against catecholamine's [12]. In the research on the effects of isoflurane and sevoflurane on the cardiovascular system, the findings for the HR are different. Apaydin and Koc [2], stated that the findings for the cardiac frequency in dogs with both isoflurane and sevoflurane are within the physiological limits. The HR increases when sevoflurane is used in dogs [37]. In one research using cats, the heart 
S. Yakan \& O. Aksoy. 2019. Comparison of the Effects of Isoflurane and Sevoflurane General Anaesthesia after Induction by Propofol on Clinical and Physiological Measurements in Calves.

ActaScientiae Veterinariae. 47: 1659.

Table 3. The blood parameters measurement results in the isoflurane and sevoflurane groups.

\begin{tabular}{|c|c|c|c|c|c|c|}
\hline $\begin{array}{c}\text { Haematological } \\
\text { parameter }\end{array}$ & Groups & $\begin{array}{l}\text { Period before } \\
\text { anaesthesia }\end{array}$ & $\begin{array}{c}\text { Premedication } \\
\text { period }\end{array}$ & $\begin{array}{l}\text { Induction } \\
\text { period }\end{array}$ & $30 \mathrm{~min}$ & $75 \mathrm{~min}$ \\
\hline \multirow{2}{*}{$\mathrm{RBC}\left(10^{6} / \mu \mathrm{L}\right)$} & Isoflurane & $8.00 \pm 0.41^{\mathrm{a}}$ & $6.89 \pm 0.41^{\mathrm{a}}$ & $7.13 \pm 0.47^{\mathrm{a}}$ & $10.7 \pm 3.21^{\mathrm{a}}$ & $7.16 \pm 0.42^{\mathrm{a}}$ \\
\hline & Sevoflurane & $8.08 \pm 0.53^{\mathrm{a}}$ & $7.18 \pm 0.44^{\mathrm{a}}$ & $8.02 \pm 0.65^{\mathrm{a}}$ & $7.69 \pm 0.63^{\mathrm{a}}$ & $6.81 \pm 0.62^{\mathrm{a}}$ \\
\hline \multirow{2}{*}{ WBC $\left(10^{3} / \mu \mathrm{L}\right)$} & Isoflurane & $11.7 \pm 1.10^{\mathrm{a}}$ & $11.4 \pm 0.98^{a}$ & $11.6 \pm 1.11^{\mathrm{a}}$ & $10.4 \pm 0.79^{a}$ & $10.3 \pm 0.79^{\mathrm{a}}$ \\
\hline & Sevoflurane & $14.2 \pm 1.64^{\mathrm{a}}$ & $12.8 \pm 1.70^{\mathrm{a}}$ & $14.2 \pm 1.64^{\mathrm{ab}}$ & $12.4 \pm 1.29^{\mathrm{ab}}$ & $8.64 \pm 1.07^{\mathrm{b}}$ \\
\hline \multirow{2}{*}{ HGB (g/dL) } & Isoflurane & $10.8 \pm 0.46^{\mathrm{a}}$ & $9.96 \pm 0.43^{\mathrm{a}}$ & $9.8 \pm 0.42^{\mathrm{a}}$ & $9.6 \pm 0.43^{\mathrm{a}}$ & $9.76 \pm 0.48^{\mathrm{a}}$ \\
\hline & Sevoflurane & $10.7 \pm 0.58^{a}$ & $9.98 \pm 0.57^{\mathrm{a}}$ & $10.9 \pm 0.80^{\mathrm{a}}$ & $10.4 \pm 0.83^{a}$ & $9.19 \pm 0.75^{\mathrm{a}}$ \\
\hline \multirow{2}{*}{$\operatorname{HCT}(\%)$} & Isoflurane & $33.0 \pm 1.77^{\mathrm{a}}$ & $30.0 \pm 1.57^{\mathrm{a}}$ & $30.4 \pm 1.65^{\mathrm{a}}$ & $33.4 \pm 1.81^{\mathrm{a}}$ & $31.4 \pm 2.08^{\mathrm{a}}$ \\
\hline & Sevoflurane & $36.0 \pm 2.65^{\mathrm{a}}$ & $31.7 \pm 2.62^{\mathrm{a}}$ & $35.0 \pm 3.36^{\mathrm{a}}$ & $34.1 \pm 2.87^{\mathrm{a}}$ & $28.7 \pm 2.26^{\mathrm{a}}$ \\
\hline \multirow{2}{*}{$\operatorname{PLT}\left(10^{3} / \mu \mathrm{L}\right)$} & Isoflurane & $923 \pm 189^{a}$ & $650 \pm 79^{a}$ & $640 \pm 74^{\mathrm{a}}$ & $720 \pm 172^{\mathrm{a}}$ & $705 \pm 83^{\mathrm{a}}$ \\
\hline & Sevoflurane & $749 \pm 147^{\mathrm{a}}$ & $666 \pm 78^{a}$ & $704 \pm 62^{\mathrm{a}}$ & $650 \pm 129^{a}$ & $643 \pm 142^{\mathrm{a}}$ \\
\hline
\end{tabular}

RBC: red blood cell count, WBC: white blood cell count, HGB: haemoglobin amount, HCT: haematocrit concentration, PLT: platelet count. a-b: in the in-group comparison, the changes that occurred among the measurements with a different letter in the same line are regarded as statistically significant $(P<0.05)$.

rate decreased with isoflurane, sevoflurane, enflurane, and halothane [23]. However, they also reported that isoflurane and sevoflurane did not cause arrhythmia. In the research carried out with rabbits, the effects of isoflurane and sevoflurane on the HR are similar [21]. On the other hand, the HR increased in the horses that were applied with isoflurane compared to those applied with sevoflurane and halothane [10]. Sevoflurane anaesthesia appears to provide superior protection to the cardiovascular system, resulting in less medical intervention needed for the cardiovascular system with sevoflurane anaesthesia. The research carried out on horses showed that the HR range was between 63-73 beats per minute during the period of anaesthesia in the isoflurane and sevoflurane groups and no significant changes in the HR were observed and no arrhythmias were detected [32]. In our research, the cardiac frequency remained within the normal physiological limits during anaesthesia in both groups. In addition, the increased HR caused by isoflurane and sevoflurane during the operation was greater in the isoflurane group. This change did not exceed the physiological limits and was not considered clinically significant. Our findings show similarities to many other research studies $[2,21,23,32]$. However, we presume that the tachycardia occurred during the premedication period in all cases in our research was due to the application of atropine in this period. We presume that the changes that occurred in the HRs of the animals in both groups during anaesthesia in our research were caused by the $\mathrm{PaCO}_{2}$ sympathetic activation that accumulated in the blood due to the condition of the animals, the metabolic activities of the calves, endotracheal intubation, rectal temperature, anaesthetic depth, surgical operation and the duration of the anaesthesia. We propose that the results of the research would vary from species to species because different species respond differently to the same medications because they have different metabolisms. In this research, clinically insignificant changes occurred in the pulse rate. These changes are consistent with the changes that occurred in the HR.

Decreased arterial blood pressure during anaesthesia is due to vasodilatation [16]. Statistical insignificant decreases in the MABP from the beginning to the end of anaesthesia was observed with isoflurane and sevoflurane [2]. Some decreases in the MABP of dogs were observed during isoflurane and sevoflurane anaesthesia compared to pre-anaesthesia values, but remained within the physiological limits [1]. In one research [32], in horses that were applied with isoflurane and sevoflurane, the differences between the groups were insignificant in terms of the arterial blood pressure. In the sevoflurane group, the measurements of the SBP, DBP and MABP dramatically decreased at 30, 45 and 60 min after administration compared to the pre-anaesthetic levels. The DBP prominently decreased, especially at $60 \mathrm{~min}$ after administration. In the isoflurane group, the systolic pressure and the MABP decreased dramatically at 45 and $60 \mathrm{~min}$ after administration. The results of the SBP, DBP and MBAP measurements decreased compared to the preanaesthetic levels in all cases. Meanwhile, at 30 and 60 min, the blood pressure increased to acceptable limits in both anaesthesia groups. The results of the measurements of the blood pressure in horses are similar between these anaesthetics. The blood pressure decreased 
after mask induction and then increased throughout the anaesthesia. The SBP measurements in horses show $4 \%$ higher results in the sevoflurane group compared to the isoflurane group. In terms of the measurements of the arterial blood pressure, the differences between the groups are reportedly insignificant [10]. The comparison of anaesthetic power of halothane, isoflurane, and sevoflurane and their cardiopulmonary effects in goats, shows that the systemic vascular resistance and the arterial blood pressure decreased dose-dependently with all anaesthetics [22]. In our research, in both groups, the changes that occurred in the measurement results of the SBP and DBP remained within the physiological limits. Our results are consistent with other researchers' results $[1,10,22,32]$. The measurement results of the SBP and DBP showed statistically significant, yet clinically insignificant, changes at $60 \mathrm{~min}$ after anaesthesia administration according to intergroup comparisons. The decreased SBP and DBP results were greater in the sevoflurane group. We associate this with the fact that the cardiac frequency is lower in the sevoflurane group.

Researchers have stated that isoflurane and sevoflurane depress respiration because of the carbon dioxide that accumulates in the blood dose-dependently [7,9]. A decreased RT value was detected in dogs that were given with isoflurane [16]. Canpolat [5] stated that in dogs that received who were applied isoflurane by masked induction, the RR had decreased quickly and then has proceeded increased into normal limits by increasing. Apaydin and Koc [2] stated that the RR were similar in dogs that received isoflurane or sevoflurane. [23] On the other hand, on cats, the RR decreased with sevoflurane, isoflurane and enflurane administration, but halothane increased [23]. The changes that occurred in the RT were similar in the isoflurane and sevoflurane groups. In the research carried out with horses in order to investigate the hemodynamic effects of isoflurane and sevoflurane, the effects of sevoflurane anaesthesia on the pulmonary system were either equal to or greater than halothane and isoflurane [10]. In goats that received isoflurane, sevoflurane or halothane, the changes that occurred in the RR showed differences that did not exceed the physiological limits in each group [22]. The RR measurement results of rabbits given isoflurane and sevoflurane [21] were reportedly similar in both groups. The statistical difference between the groups was regarded as insignificant. In our research, the RR measurement results remained within the normal levels, which is consistent with the literature [34]. The degree of the changes in the results for isoflurane was not different from sevoflurane. In our research, we compared the respiratory parameters, the cardiac parameters, the RR, and the SBP, DBP and MABP between isoflurane and sevoflurane groups. The results that we obtained for the isoflurane and sevoflurane groups are similar, which is consistent with the information that the effects of both of these anaesthetic agents are similar in different animal species. The results of our research correspond to the literature $[2,21,22,34]$. The cardiovascular effects were controlled periodically in this research and when the HR and RR exceeded the physiological limits, the HR and RR were manipulated by changing the depth of the anaesthesia, sometimes by reducing the anaesthesia, using $\mathrm{O}_{2}$ support, or by artificial ventilation of the lungs without the need for another application.

The RT of all of the patients that received anaesthesia decreased. This decrease is associated with the slowing of the metabolism due to anaesthesia and the decreased need for energy $[5,16,20]$. In this research, as a result of a $75 \mathrm{~min}$ of anaesthesia, statistically, significant decreases in RT were observed at all sampling times. This decrease was found to be $1-2^{\circ} \mathrm{C}$ on average. The possible cause of this decrease is the slowing of the metabolism as a result of the anaesthesia, the application of the operation, the loss of blood, evaporation due to operative exposure and the room temperature. The changes in RT caused by both anaesthetics are similar. To avoid hypothermia, hot mats were used, a heater was provided in the room, and the wet serviettes on the animal were changed frequently.

In both anaesthesia groups, the changes that occurred in the P wave, the PR interval, and in the QRS, R and T waves remained within the reference values given in the literature [14]. Based on the results of this research, it has been concluded that isoflurane and sevoflurane do not have any negative effects on the ECG. Both anaesthetic agents have similar effects on the ECG. Our results confirm the view [24,26] that isoflurane and sevoflurane do not have any negative effects on the ECG.

One of the important indicators of the effect levels from anaesthesia of the tissue and organ systems is the changes that occur in the blood parameters [12]. In our research, when the changes in the blood parameters caused by isoflurane and sevoflurane after 
propofol induction were examined, the results were similar to many other researchers' $[5,12,16,19,24]$. The dramatic changes throughout anaesthesia in terms of the amount of haemoglobin and haematocrit, the red blood cell count, the white blood cell and the platelet count were not statistically significant, which may be associated with good tissue perfusion.

\section{CONCLUSION}

Since no serious complications occurred with either anaesthetic option, we have concluded that isoflurane and sevoflurane have similar effects on the cardiopulmonary systems of calves. In addition, the effects of propofol, which is used for anaesthesia induction, have been evaluated and observed and this drug is an effective and reliable option to initiate anaesthesia. The research on the use of this anaesthetic in calves is limited and most of the existing studies investigated its combination with injectable anaesthetics [4,20]. As a result, in this research, we concluded that isoflurane and sevoflurane induce similar physiological measurement results, blood parameters, and ECG results and that both anaesthetics cause minimal complications.

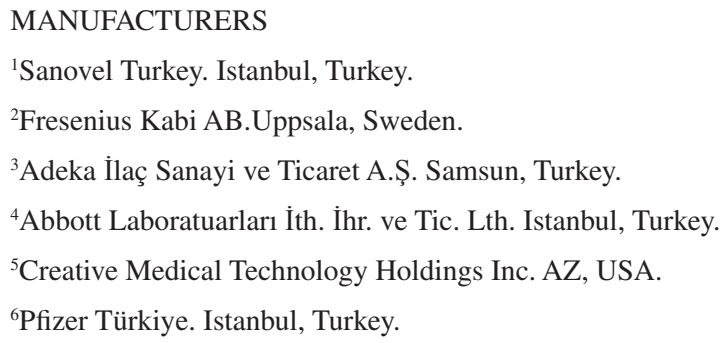

Funding. This study (It is abstract of the unpublished $\mathrm{PhD}$ thesis) was supported by the Kafkas University Scientific Research Projects Committee (VF-57).

Ethical approval. The study was approved by The Animal Local Ethics Committee (KAÜ, HAYDEK Number: 2010-080), Kafkas University.

Declaration of interest. The authors report no conflicts of interest. The authors alone are responsible for the content and writing of the paper.

\section{REFERENCES}

1 Apaydin N. \& Kibar M. 2008. Effects of isoflurane and sevoflurane anaesthesia on cardiovascular system during the experimental laparotomy of dogs. Journal of Health Sciences. 7(3): 162-167.

2 Apaydin N. \& Koc B. 2005. Comparison of the effects of isoflurane and sevoflurane anaesthesia on hemodynamic and biochemical parameters in dogs. Veteriner Cerrahi Dergisi. 11(1/4): 31-35.

3 Bednarski R.M. \& Muir III W.W. 1991. Closed system delivery of halothane and isoflurane with a vaporize in the anesthetics circle. Veterinary Surgery. 20 (5): 353-356.

4 Bettschart-Wolfensberger R., Semder A., Alibhai H., Demuth D., Aliabadi F.S. \& Clarke K.W. 2000. Cardiopulmonary side-effects and pharmacokinetics of an emulsion of propofol (Disoprivan ${ }^{\circledR}$ ) in comparison to propofol solved in polysorbate 80 in goats. Journal of Veterinary Medicine A. Physiology, Pathology, Clinical Medicine. 47(6): 341-350.

5 Canpolat I. 1992. Köpeklerde yeni bir inhalasyon anesteziği olan isoflurane ile halothane' nin karşılaştırılması. Journal of the Faculty of Veterinary Medicine, Firat University. 6: 1-2.

6 Cantalapiedra A.G., Villanueva B. \& Pereira J.L. 2000. Anaesthetic potency of isoflurane in cattle: Determination of the minimum alveolar concentration. Veterinary Anaesthesia and Analgesia. 27(1): 22-26.

7 Cecen G., Topal A., Gorgul O.S. \& Akgoz S. 2009. The cardiopulmonary effects of sevoflurane, isoflurane and halothane anaesthesia during spontaneous or controlled ventilation in dogs. Journal of the Faculty of Veterinary Medicine, Ankara University. 56: 255-261.

8 Crystal G.J., Zhou X., Gurevicius J., Czinn E.A., Salem M.R., Alam S., Piotrowski A. \& Hu G. 2000. Direct coronary vasomotor effects of sevoflurane and desflurane in in situ canine hearts. Anesthesiology. 292: 1103-1113.

9 Dagli R. 2013. Effects of sevoflurane, isoflurane, and propofol on thyroid function. Cumhuriyet Medical Journal. 35 : 373-381.

10 Driessen B., Nann L., Benton R. \& Boston R. 2006. Differences in need for hemodynamic support in horses anesthetized with sevoflurane as compared to isoflurane. Veterinary Anaesthesia and Analgesia. 33(6): 356-367.

11 Duke T. 1995. A new intravenous anesthetic agent: propofol. Canadian Veterinary Journal. 36(3): 181-183.

12 Duzgun O. \& Perk E.C. 1998. Köpeklerde ketamin indüksiyonu ile gerçekleştirilen isofluran anestezisi ve kan tablosuna etkileri üzerine araştırmalar. Journal of the Faculty of Veterinary Medicine, Istanbul University. 24: 379-401. 
13 Ebert T.J., Harkin C.P. \& Muzi M. 1995. Cardiovascular responses to sevoflurane: A review. Veterinary Anaesthesia Analgesia. 81: 11-22.

14 Espino L., Suarez L.M., Lopez-Becerio A. \& Santamarina G. 2001. Electrocardiogram reference values for the buzzard. Journal of Wildlife Diseases. 37(4): 680-685.

15 Greene S.A., Keegan R.D., Valdez R.A. \& Knowles D.K. 2002. Cardiovascular effects of sevoflurane in Holstein's calves. Veterinary Anaesthesia and Analgesia. 29(2): 59-63.

16 Gunay C. \& Unsaldi S. 2000. The effects of enflurane, isoflurane and propofol anesthetics on blood parameters in dogs. Journal of the Faculty of Veterinary Medicine, Firat University. 14(1): 129-135.

17 Guzel O., Perk E.C., Aktas M. \& Devecioglu Y. 2005. Administration of inhalation in rabbits using the endotracheal intubation technique. Journal of the Faculty of Veterinary Medicine, Istanbul University. 3: 139-148.

18 Hall L.W., Clarke K.W. \& Trim C.M. 2001. Principle of sedation, analgesia and premedication in veterinary anaesthesia. In: Veterinary Anaesthesia. 10th edn. London: WB Saunders, pp.75-112.

19 Hayat A. \& Bulut S. 2003. Comparison of effects on some hematological and biochemical values and recovery from anaesthesia of halothane and sevoflurane in dogs. Eurasian Journal of Veterinary Science. 19: 49-54.

20 Hayat A., Sindak N. \& Karacal N. 2006. The use of propofol in Kilis goats. Doğu Anadolu Bölgesi Araştırmaları. 36-39.

21 Hedenqvist P., Roughan J.V., Antunes L., Orr H. \& Flecknell P.A. 2001. Induction of anaesthesia with desflurane and isoflurane in the rabbit. Laboratory Animals. 35(2): 172-179.

22 Hikasa Y., Hokushin S., Takase K. \& Ogasawara S. 2002. Cardiopulmonary, hematological, serum biochemical and behavioral effects of sevoflurane compared with isoflurane or halothane in spontaneously ventilating goats. Small Ruminant Research. 43(2): 167-178.

23 Hikasa Y., Ohe N., Takase K. \& Ogasawara S. 1997. Cardiopulmonary effects of sevoflurane in cats: comparison with isoflurane, halothane, and enflurane. Research in Veterinary Science. 63(3): 205-210.

24 Hikasa Y., Saito K., Takase K. \& Ogasawara S. 2000. Clinical, cardiopulmonary, hematological and serum biochemical effects of sevoflurane and isoflurane anaesthesia in oxygen under spontaneous breathing in sheep. Small Ruminant Research. 36(3): 241-249.

25 Lee L. 2010. Ruminant \& swine anesthesia. Veterinary Surgery I. VMED 7412: 1-15.

26 Martin M.F., Carrosco M.S., Gargallo J.U. \& Ezquerra L.J. 2002. Endocrine, haematological and metabolic responses to sevoflurane anaesthesia in lambs. Veterinary Anaesthesia and Analgesia. 28(3): 132-139.

27 Muir W.W. 2007. Considerations for general anesthesia. In: Thurmon J.C. Tranquilli W.J. \& Grimm K.A. (Eds). Lumb Jones Veterinary Anesthesia and Analgesia. 4th edn. Ames: Blackwell, pp.7-30.

28 Mutoh T., Kanamura A., Suzuki H., Tsubone H., Nishimura R. \& Sasaki N. 2001. Respiratory reflexes in spontaneously breathing anesthetized dogs in response to nasal adminitration of sevoflurane, isoflurane or halotane. American Journal of Veterinary Research. 62(3): 311-319.

29 Mutoh T., Nishimura R. \& Sasaki N. 2001. Effects of nitrous oxide on mask induction of anaesthesia with sevoflurane or isoflurane in dogs. American Journal of Veterinary Research. 62(11): 1727-1733.

30 Ozaydin I., Atalan G., Uzun M., Kilic E. \& Cenesiz M. 2001. Assessment of anesthetic properties and clinical, cardiovascular and respiratory effects of medetomidine, propofol and ketamine combination in dogs. Journal of the Faculty of Veterinary Medicine, Kafkas University. 7(1): 71-76.

31 Ozturk A. \& Altug ME. 2007. Effects of repeated application of isoflurane and desflurane on electrocardiogram anaesthesia induction and recovery characteristics in rats. Bulletin of the Veterinary Institute in Pulawy. 51: 635-640.

32 Read M.R., Read E.K., Duke T. \& Wilson D.G. 2002. Cardiopulmonary effects and induction and recovery characteristics of isoflurane and sevoflurane in foals. Journal of the American Veterinary Medical Association. 221(3): 393-398.

33 Reid J., Nolan A.M. \& Welsh E. 1993. Propofol as an induction agent in the goat: a pharmacokinetic study. Journal of the Veterinary Pharmacology Therapeutics. 16(4): 488-493.

34 Reibold T.W. 2015. Ruminants. In: Grimm K.A., Lamont L.A., Tranquilli W.J., Greene S.A. \& Robertson S.A. (Eds). Lumb Jones Veterinary Anesthesia and Analgesia. 5th edn. Ames: Blackwell, pp.912-927.

35 Skarda R.T., Bednarski R.M., Muir W.W. \& Hubbell J.A.E. 1995. Inhalation Anesthesia. Handbook of Veterinary Anesthesia. Philadelphia: WB Saunders, pp.133-141. 
36 Steffey P.E. \& Mama K.R. 2007. Inhalation anesthetics. In: Thurmon J.C. Tranquilli W.J. \& Grimm K.A. (Eds). Lumb Jones Veterinary Anesthesia and Analgesia. 4th edn. Ames: Blackwell, pp.355-393.

37 Teixeira F.J., Luna S.P.L., Cruz M.L., Braz J.Z., Massone F. \& Nogueira C.S. 2007. A study of the effect of hemorrhage on the cardiorespiratory actions of halothane, isoflurane, and sevoflurane in the dog. Veterinary Anaesthesia and Analgesia. 34(2): 107-116.

38 Topal A. 2005. Veteriner Anestezi. Bursa: Nobel \& Güneş, pp.107-128. 